Biochimica et Biophysica Acta, 608 (1980) 39-46

(C) Elsevier/North-Holland Biomedical Press

BBA 99670

\title{
THE ROLE OF EIF-4C IN PROTEIN SYNTHESIS INITIATION COMPLEX FORMATION
}

\begin{abstract}
HANS GOUMANS, ADRI THOMAS, ADRIE VERHOEVEN, HARRY O. VOORMA and ROB BENNE

Department of Molecular Cell Biology, University of Utrecht, Transitorium III, Padualaan 8, $3584 \mathrm{CH}$ Utrecht (The Netherlands)
\end{abstract}

(Received December 7th, 1979)

Key words: Initiation factor eIF-4C; Complex assembly; Protein synthesis

\section{Summary}

eIF-4C has a pronounced stimulatory effect on initiation complex formation with native $80-S$ ribosomes $\left(80-S_{n}\right)$ as the only source of ribosomal subunits, but only a small effect when washed $40-\mathrm{S}$ subunits are used.

eIF- $4 \mathrm{C}$ is accessary to eIF-3 in dissociating $80-S_{n}$ ribosomes.

eIF-4C is present on $40-S_{n}$ but absent on $40-S_{n}$ dimers, which occur in preparations of native ribosomes and are as such inactive in protein synthesis.

eIF-4C dissociates $40-S_{n}$ dimers into active monomers. These results can be explained by assuming that the presence of eIF-4C on $40-S_{n}$ prevents:

(a) premature association with 60-S ribosomal subunits and

(b) dimerisation, thus increasing the rate and extent of initiation complex formation.

\section{Introduction}

Initiation of protein synthesis in cell-free systems derived from eukaryotic cells proceeds via a complex sequence of events in which at least eight initiation factors participate [2-4]. In one of the first steps a ternary complex of initiation factor 2 (eIF-2), methionyl-tRNA $A_{f}$ and GTP binds to the small ribosomal subunit $[5,6]$. This reaction is stimulated by two other factors eIF-3 $\left(M_{\mathbf{r}}\right.$ $750000)$ and eIF-4C $\left(M_{\mathrm{r}} 17500\right)[2,3,4]$.

The interaction between eIF-3 and the $40 \mathrm{~S}$ ribosomal subunit in a stoichiometric fashion has been demonstrated $[2,4,7]$, which seems to indicate that the 
presence of eIF-3 on the $40 \mathrm{~S}$ subunit is required either to prevent its premature association with $60 \mathrm{~S}$ or to stabilize the nascent $40 \mathrm{~S}$ initiation complex [8].

The role of eIF-4C is much less clear, particularly because the observed stimulatory effects are small (1.5-fold) and attempts to demonstrate the presence of eIF-4C on the complex at any stage of the initiation process have failed $[2-4,8]$.

The present study deals with the role of eIF-4C in initiation of protein synthesis. We find that the stimulatory activity of eIF-4C in the initiation of protein synthesis can be explained by its effect on the dissociation of $80-S_{n}$ ribosomes and the subsequent prevention of the formation of $40-S_{n}$ dimers, which are inactive in protein synthesis.

\section{Materials and Methods}

Biological compounds. Highly purified initiation factors from rabbit reticulocytes and rabbit liver tRNA were prepared according to Voorma et al. [9] and to Benne et al. [10]. [ $\left.{ }^{3} \mathrm{H}\right]$ Methionyl-tRNA (Met-tRNA $_{\mathrm{f}}$ ), spec. act. 4500 $\mathrm{cpm} / \mathrm{pmol}$, was prepared according to Bose et al. [11] as modified by Stanley [12]. Washed ribosomal subunits were prepared according to Schreier and Staehelin [13].

Binding of $\left[{ }^{3} \mathrm{H}\right] \mathrm{Met}$-tRNA $A_{f}$ to $40 \mathrm{~S}$. Binding of $\left[{ }^{3} \mathrm{H}\right] \mathrm{Met}-\mathrm{tRNA} \mathrm{f}_{\mathrm{f}}$ to $40 \mathrm{~S}$ and analysis of the assay mixtures was performed as described by Van der Mast et al. [14]. A typical assay mixture contained in a final volume of $25 \mu \mathrm{l}: 20 \mathrm{mM}$ Hepes-KOH (pH 7.6)/1 mM ATP/0.4 mM GTP/5 mM creatine phosphate $/ 1 \mathrm{mM}$ dithiotreitol/120 $\mathrm{mM} \mathrm{K}(\mathrm{Ac})_{2} / 2 \mathrm{mM} \mathrm{Mg}(\mathrm{Ac})_{2} / 0.1 \mathrm{mM}$ spermine $/ 10 \mathrm{pmol}\left[{ }^{3} \mathrm{H}\right]$ Met-tRNA $\mathrm{f}_{\mathrm{f}} / 0.05$ units of creatine kinase and ribosomes and initiation factors as indicated in the figure legends.

After incubating at $37^{\circ} \mathrm{C}$ for $15 \mathrm{~min}, 75 \mu \mathrm{l}$ ice-cold buffer containing $20 \mathrm{mM}$ Tris- $\mathrm{HCl}(\mathrm{pH} 7.6) / 3 \mathrm{mM} \mathrm{Mg}(\mathrm{Ac})_{2} / 100 \mathrm{mM} \mathrm{KCl}$ and $7 \mathrm{mM}$ 2-mercaptoethanol (Buffer A) was added.

The samples were then layered on isokinetic gradients of $10 \%$ to $30 \%$ sucrose in buffer A. After centrifugation, fractions of $250-\mu \mathrm{l}$ were collected and counted.

Preparation of $80 S_{n}, 60 S_{n}+40 S_{n d}$ and $40 S_{n}$. Reticulocyte lysate was prepared as described by Schreier and Staehelin [15]. $250 \mathrm{ml}$ lysate was centrifuged for $35 \mathrm{~min}$ at $60000 \mathrm{rev} . / \mathrm{min}$ in a $60-\mathrm{Ti}$ rotor to remove the polyribosomes.

The supernatant was centrifuged for $16 \mathrm{~h}$ at $45000 \mathrm{rev} . / \mathrm{min}$ in the same rotor. The pellets from the second centrifugation were resuspended in buffer $B$ (20 mM Tris-HCl ( $\mathrm{pH} 7.6) / 100 \mathrm{mM} \mathrm{KCl} / 4 \mathrm{mM} \mathrm{Mg}(\mathrm{Ac})_{2} / 14 \mathrm{mM}$ 2-mercaptoethanol) containing $0.25 \mathrm{M}$ sucrose. The ribosome suspension was loaded on a $10 \%$ to $40 \%$ isokinetic gradient in buffer B in a B XIV zonal rotor. After centrifugation for $4 \mathrm{~h}$ at $48000 \mathrm{rev} . / \mathrm{min}, 50$ fractions of $10 \mathrm{ml}$ were collected, from which the absorbance at $260 \mathrm{~nm}$ was measured. The ribosomes from the $80-\mathrm{S}$, $60-\mathrm{S}$ and $40-\mathrm{S}$ regions were pelleted in a $60-\mathrm{Ti}$ rotor for $16 \mathrm{~h}$ at $40000 \mathrm{rev} . /$ min. The pellets were resuspended in buffer A with $0.25 \mathrm{M}$ sucrose. The purity of the preparations was determined on analytical gradients of 15 to $32 \%$ 
sucrose in buffer B containing 100 or $500 \mathrm{mM} \mathrm{KCl}$. The profiles are shown in Fig. 1.

Panels A, B and C represent the analysis of $40 S_{n}, 60 S_{n}$ and $80 S_{n}$ on low salt gradients, whereas panels $\mathrm{D}, \mathrm{E}$ and $\mathrm{F}$ give the results of the high salt gradients.

From panel $D$ it is obvious that the $40 S_{n}$ preparation is over $90 \%$ pure. Panel A, however, reveals a strong tendency of this particle to dimerise in low salt gradients. Panel $\mathrm{C}$ shows that the $80 \mathrm{~S}_{\mathrm{n}}$ preparation is over $90 \%$ pure, since equimolar amounts of $40 \mathrm{~S}$ and $60 \mathrm{~S}$ arise from high salt induced dissociation (panel F). The occurence of $40-S_{n}$ dimers $\left(40 S_{n d}\right)$ in otherwise homogeneous 60-S preparations, which explains the contamination of 60-S ribosomal subunit preparations with $40-\mathrm{S}$ subunits, has been observed by others $[16,17]$. This is clear when panel B $(60 \mathrm{~S}$, low salt) is compared to panel $\mathrm{E}(60 \mathrm{~S}$, high salt): the preparation of seemingly homogeneous $60-S_{n}$ subunits appeared to be contaminated for at least $50 \%$ with $40-\mathrm{S}_{\mathrm{n}}$ dimers. A typical preparation yielded: 50 $A_{260}$ units of $40 \mathrm{~S}_{\mathrm{n}}, 30 A_{260}$ units of $60 \mathrm{~S}_{\mathrm{n}}$ (including $40 \mathrm{~S}_{\mathrm{nd}}$ ) and $550 A_{260}$ units of $80 \mathrm{~S}_{\mathrm{n}}$.

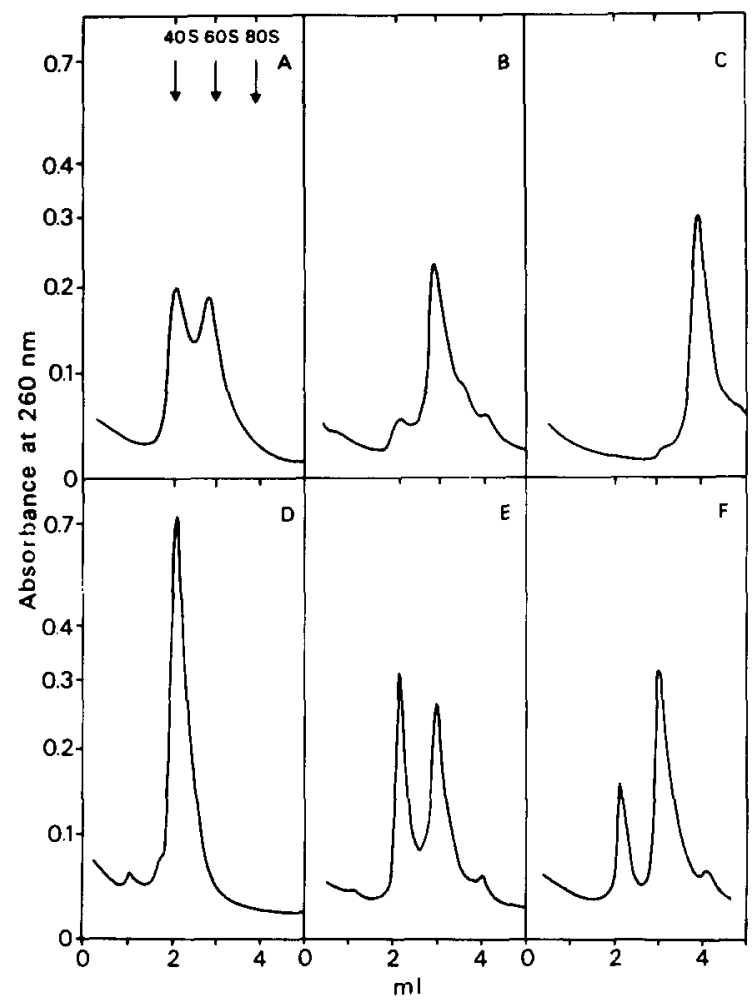

Fig. 1. Analytical sucrose gradients of $40 \mathrm{~S}_{\mathrm{n}}, 60 \mathrm{~S}_{\mathrm{n}}$ and $80 \mathrm{~S}_{\mathrm{n}} \cdot 0.75 \mathrm{~A}_{260}$ unit of each preparation was layered on a $15 \%$ to $32 \%$ isokinetic gradient and centrifuged for $90 \mathrm{~min}$ at $50000 \mathrm{rev} . / \mathrm{min}$ at $4^{\circ} \mathrm{C}$ in the SW 50.1 rotor. Panel $A$ and $D, 40 S_{n}$; panel $B$ and E, $60 \mathrm{~s}_{n}$; panel $C$ and F, $80 S_{n}$. Panel A, B and C, 100 $\mathrm{mM} \mathrm{KCl}$; Panel D, E and F, $500 \mathrm{mM} \mathrm{KCl}$. 


\section{Results and Discussion}

\section{The effect of eIF-4C on dissociation}

A prerequisite for the utilization of $80-S_{n}$ ribosomes in protein synthesis is their dissociation into subunits. Therefore, any factor inducing dissociation will stimulate in an assay for initiation of protein synthesis with $80 S_{n}$ as the only source of ribosomal subunits. In order to exclusively determine the effect of eIF-4C on the dissociation, we have compared the dependency on eIF-4C of the methionyl-puromycin formation with $80-\mathrm{S}_{\mathrm{n}}$ and with salt-derived ribosomal subunits. The results are shown in Fig. 2. With $80-\mathrm{S}_{\mathrm{n}}$ ribosomes (Fig. 2A) the effect of eIF-4C on the methionyl-puromycin synthesis is pronounced. Almost 4 -fold stimulation in the absence of eIF-3, 2-fold in its presence. On the other hand, when salt-derived subunits were used and 40-S initiation complexes were allowed to form prior to the addition of $60 \mathrm{~S}$ and puromycin, only a small stimulatory effect of eIF-4C was observed, 1.6-fold in the absence of eIF-3 and 1.1-fold in its presence (Fig. 2B), although the overall level of methionyl-puromycin synthesis with both classes of ribosomes was the same. From these results it is clear that in a system in which dissociation of 80-S ribosomes prior to initiation of protein synthesis does not need to occur, the effect of eIF- $4 \mathrm{C}$ is small.

Furthermore, upon the addition of eIF-3, the effect of eIF-4C decreases both with $80-S_{n}$ and with salt-derived ribosomal subunits, suggesting that eIF-3 also partcipates in the dissociation of $80-\mathrm{S}$ ribosomes, in agreement with the results of other groups $[2,3]$.

The participations of eIF-4C in the dissociation was tested in an assay system directly measuring the extent of dissociation of $80-\mathrm{S}_{\mathfrak{n}}$ ribosomes under the

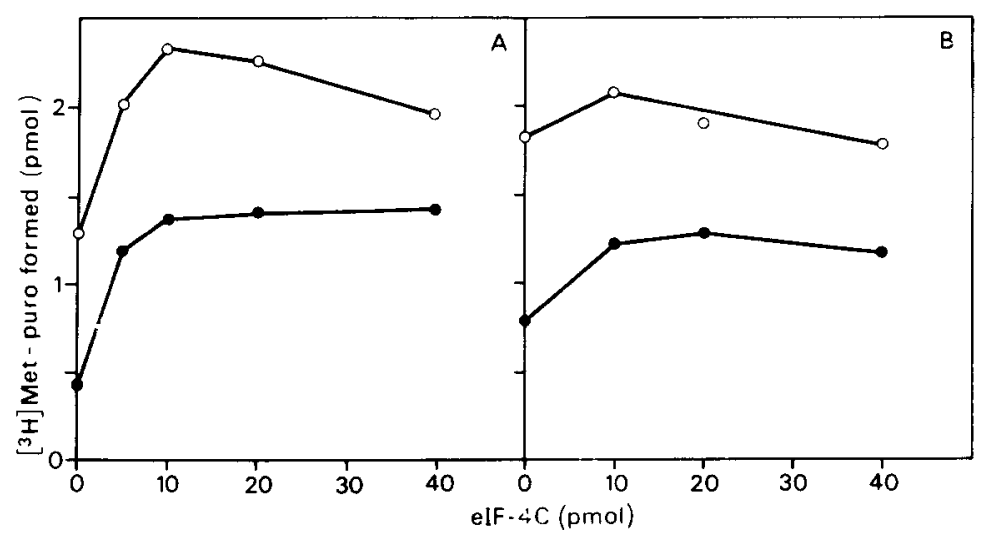

Fig. 2. Titration of eIF-4C in the assay for methionyl-puromycin synthesis. Panel A: Methionyl-puromycin formation with $80 \mathrm{~S}_{\mathbf{n}}$. The assay for the synthesis of methionyl-puromycin was performed according to Thomas et al. [18]. Formed methionyl-puromycin was extracted according to Leder and Bursztyn [19]; background synthesis, obtained in the absence of ribosomes was subtracted. Indicated amounts of eIF-4C were added to reaction mixtures containing $10 \mathrm{pmol}$ of $80 \mathrm{~S}_{\mathbf{n}}$, both in the absence $(\bullet-\bullet)$ and presence $(O-\infty)$ ) of $10 \mathrm{pmol}$ of eIF-3. Panel B: Methionyl-puromycin formation with salt-washed ribosomal subunits. The same as for panel $A$, but instead of $80 \mathrm{~S}_{\mathrm{n}} 10 \mathrm{pmol}$ of salt-washed 40-S and $60-\mathrm{S}$ ribosomal subunits were used. Prior to the addition of $60 \mathrm{~S}$ and puromycin, $40 \mathrm{~S}$ initiation complexes were allowed to form by incubating for $5 \mathrm{~min}$ at $37^{\circ} \mathrm{C}$. 
ionic conditions used in the experiments described in Fig. 2. The results are shown in Fig. 3.

Indeed eIF-4C has a distinct, although small, effect on the dissociation of 80 $80-S_{n}$ ribosomes. This effect could be measured both in the absence and presence of eIF-3. The effects of eIF-3 and eIF-4C were additive, in agreement with the results of Fig. 2.

Exchange experiments (not shown) with ${ }^{3} \mathrm{H}$-labeled $40-\mathrm{S}$ subunits and $80-\mathrm{S}_{\mathrm{n}}$ ribosomes revealed that eIF-4C enhanced the rate of the incorporation of ${ }^{3} \mathrm{H}$-labeled $40-\mathrm{S}$ subunits into $80 \mathrm{~S}$, suggesting that eIF-4C increases both the
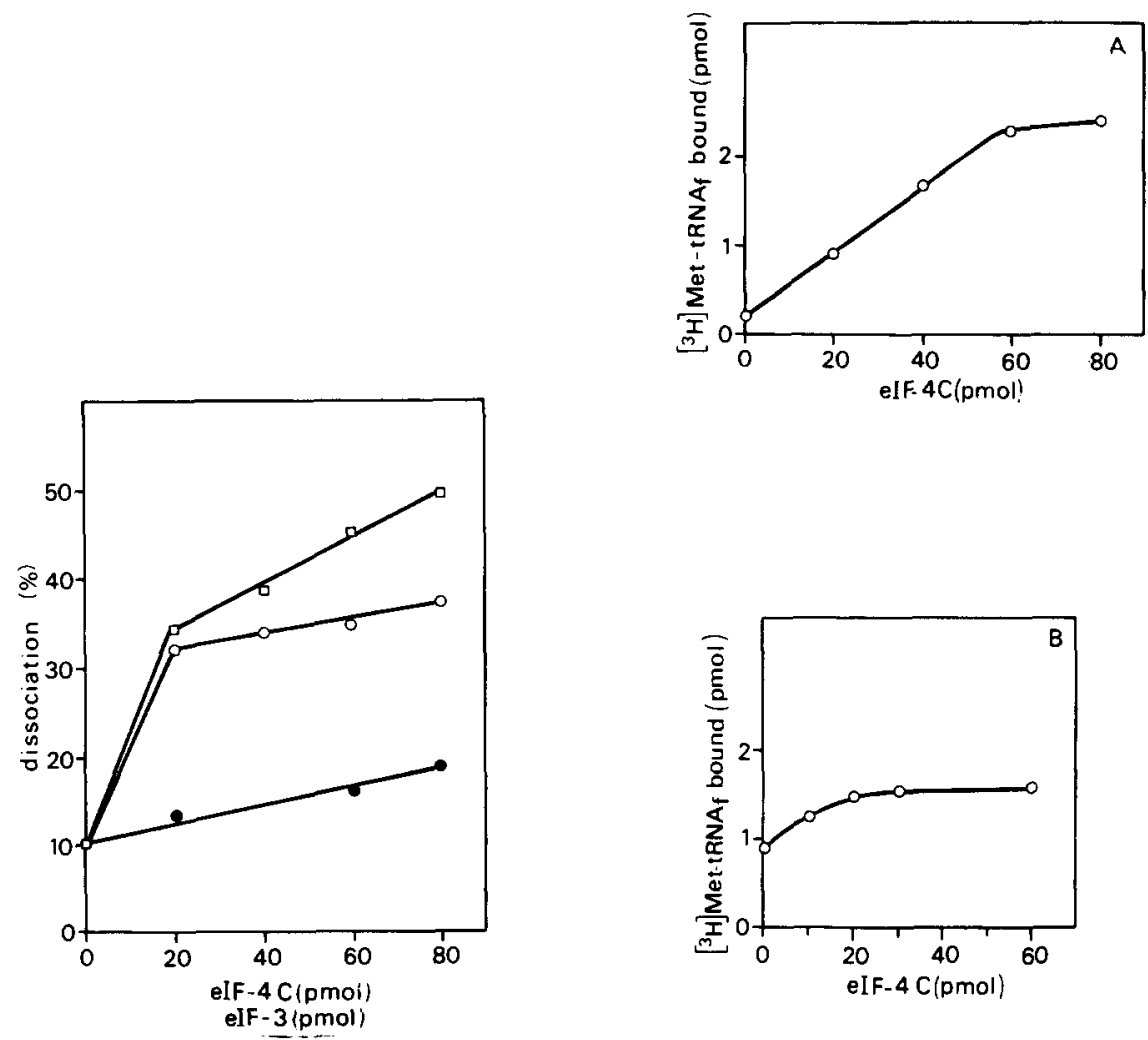

Fig. 3. Dissociation of $80 \mathrm{~S}_{\mathrm{n}}$. Reaction mixtures were incubated under the ionic conditions of the [ ${ }^{3} \mathrm{H}$ ]Met-tRNA $A_{f}$ binding assay; the energy system was omitted, the $\mathrm{Mg}^{2+}(\mathrm{Ac})_{2}$ concentration was $0.6 \mathrm{mM}$. Reaction mixtures containing $1 A_{260}$ unit of $80 \mathrm{~S}_{\mathrm{n}}$ and indicated amounts of eIF-3 and eIF-4C, were incubated for $15 \mathrm{~min}$ at $37^{\circ} \mathrm{C}$, whereafter gluteraldehyde was added to a final concentration of $0.1 \%$. The mixtures were analyzed on sucrose gradients as described by Naaktgeboren et al. [20]. The level of dissociation is calculated from the absorbance profiles as:

\section{$\frac{40 s+60 s}{40 s+60 s+80 s} \times 100 \%$}

$-\longrightarrow$, titration of eIF-4C, no eIF-3; $\bigcirc \longrightarrow$, titration of eIF-3, no eIF-4C; $\square \longrightarrow \square$, titration of $\mathrm{elF}-3$, in the presence of $80 \mathrm{pmol} e I F-4 \mathrm{C}$.

Fig. 4. Titration of eIF-4C in the Met-tRNA $A_{f}$ binding assay. Panel A: Met-tRNA $A_{f}$ binding to $40 S_{\text {nd }}$. Reaction mixtures containing $19 \mathrm{pmol} 40 \mathrm{~S}_{\mathrm{nd}}, 16 \mathrm{pmol}$ eIF-2 and the indicated amounts of eIF-4C were incubated as described in Materials and Methods. Panel B: Met-tRNA $A_{f}$ binding to $40 \mathrm{~S}$. Reaction mixtures containing $10 \mathrm{pmol}$ of washed $40 \mathrm{~S}, 16 \mathrm{pmol}$ eIF-2 and the indicated amounts of eIF-4C were incubated as described in Materials and Methods. 
$k_{1}$ and $k_{2}$ (although not to the same extent) of the equilibrium reaction:

$80 \mathrm{~S} \underset{k_{2}}{\stackrel{k_{1}}{\rightleftharpoons}} 40 \mathrm{~S}+60 \mathrm{~S}$

\section{Dependency on eIF-4C of 40 S-initiation complex formation}

Part of the stimulation by $\mathrm{eIF}-4 \mathrm{C}$ of the initiation of protein synthesis may be explained by its effect on the dissociation equilibrium of 80-S ribosomes (Figs. 2 and 3). However, studies on the formation of 40-S initiation complexes which utilize 40-S ribosomal subunits as the sole source of ribosomes still show a small but consistent stimulatory effect with eIF-4C $[2,3,6,8]$. Such an effect of elF-4C could not be explained by a stabilization of the Met-tRNA-binding [8] or the binding of other initiation factors (results not shown).

An indication as to what may be the cause of this stimulation comes from studies using native $40-\mathrm{S}$ dimers $\left(40-\mathrm{S}_{\mathrm{nd}}\right)$. The tendency of $40-\mathrm{S}$ ribosomes to dimerize has long been recognized [15,16]. From the results of Fig. 1 it became clear that a considerable (50\%) part of the native 40-S ribosomal subunits is isolated as a dimer sedimenting at approx. $60 \mathrm{~S}$.

We have performed the assay on $40 \mathrm{~S}$ initiation complex formation with $40 \mathrm{~S}_{\mathrm{nd}}$, obtained as described in the legend to Fig. 1, and determined the effect of eIF-4C. The results are given in Fig. 4A. First of all, such dimers are quite stable upon centrifugation at low salt gradients (compare Fig. 1) and are, as such, virtually inactive in the assay system: hardly any Met-tRNA $\mathrm{A}_{\mathrm{f}}$ could be detected in the $40 \mathrm{~S}$ position if no eIF-4C was added. The addition of eIF- $4 \mathrm{C}$ resulted in a drastic increase (up to 10 -fold) of the Met-tRNA $A_{\mathrm{f}}$ binding reaching normal values of Met-tRNA $A_{f}$ bound per $40 \mathrm{~S}$ added.

On the other hand, only a small stimulation (1.4-fold) by eIF-4C was observed when the experiment was performed with washed ribosomal 40-S subunits (Fig. 4B), (in line with the results of Fig. 2B and completely in agreement with literature values $[2,3,4]$ ), although the level of Met-tRNA $A_{f}$ binding to both classes of subunits was the same, provided that excess eIF-4C was present.

\section{'Dedimerisation' of $40 S_{n d}$}

The possibility arises that eIF-4C converts inactive 40-S dimers into monomers, which are active in the initiation of polypeptide synthesis. Therefore, we investigated the effect of $\mathrm{eIF}-4 \mathrm{C}$ on the sedimentation behaviour of 40-S dimers. Fig. 5 shows that upon incubation of $40 \mathrm{~S}_{\mathrm{nd}}$ with increasing amounts of eIF-4C under the ionic conditions of protein synthesis an increasing 'dedimerisation' can be observed. Such an increase in monomers is correlated with an increase in activity in the assays for initiation (see Fig. 4). Furthermore, a pronounced additional stimulation of 'dedimerisation' occurred in the presence of all the components required for $40 \mathrm{~S}$ initiation complex formation.

The process of 'dedimerisation' and subsequent formation of a $40 \mathrm{~S}$ initiation complex can be represented by the following equation:

$40 \mathrm{~S}_{\text {nd }} \stackrel{k_{1}}{\stackrel{k_{2}}{\rightleftharpoons}} 40 \mathrm{~S} \underset{\begin{array}{l}\text { initiation } \\ \text { factors } \\ \text { Met-tRNA }\end{array} \text {, AUG }}{\longrightarrow} 40 \mathrm{~S}$ initiation complex 
In this scheme the effect of eIF-4C is explained by an increase of the $k_{1}$, whereas the addition of other factors and Met-tRNA $\mathrm{f}_{\mathrm{f}}$ will result in an overall decrease of the dimer-level.

\section{$40-S_{n}$ dimers do not contain eIF-4C}

The results of Figs. 4 and 5 are puzzling particularly because a physiological role of 40-S dimers is not immediately obvious. Isolation procedures of ribosomal subunits might remove eIF $-4 \mathrm{C}$ from the $40 \mathrm{~S}$ subunit, which could result in dimerisation of the particle. In this respect it should be pointed out that
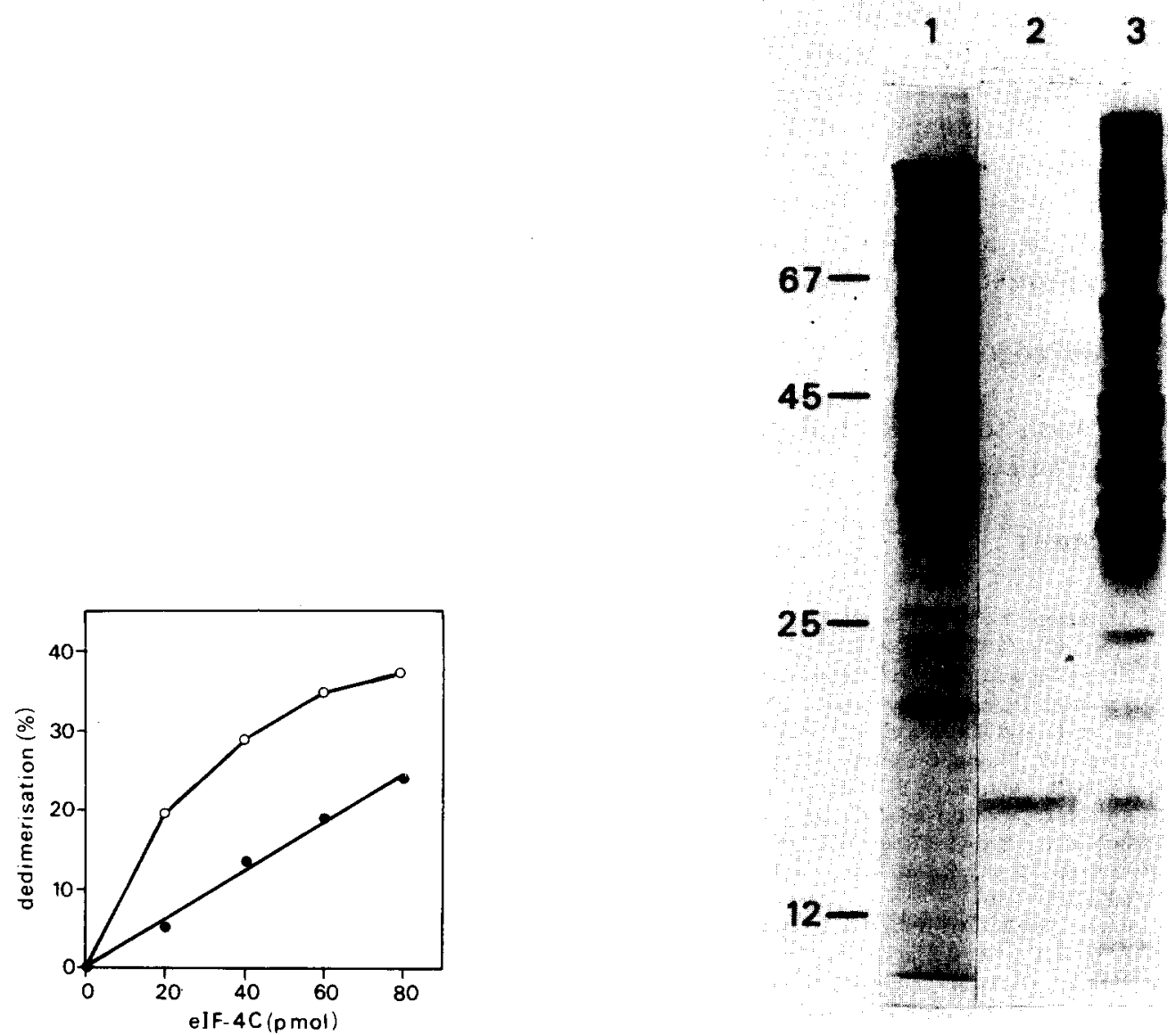

Fig. 5. 'Dedimerisation' of $40 \mathrm{~S}_{\mathrm{nd}}$. $0.7 \mathrm{~A}_{260}$ unit of $40 \mathrm{~S}_{\mathrm{nd}}$ was incubated with the indicated amounts of eIF-4C under the ionic conditions of the Met-tRNA $f$ binding assay without any further addition $(\bullet)$, or in the complete system $(\circ-\infty)$. 'Dedimerisation' was calculated from the absorbance

$\frac{40 s_{n}}{40 s_{n d}+40 s_{n}} \times 100 \%$

Fig. 6. Polyacrylamide gel electrophoresis of $0.5 \mathrm{M} \mathrm{KCl}$ washes of $40 \mathrm{~S}_{\mathrm{n}}$ and $40 \mathrm{~S}_{\mathrm{nd}} \cdot 0.5 \mathrm{M} \mathrm{KCl}$ wash was prepared from $40 \mathrm{~S}_{\mathrm{n}}$ and $40 \mathrm{~S}_{\mathrm{nd}}\left(6 \mathrm{~A}_{2} 60\right.$ units each), following standard procedures. The washed were subjected to electrophoresis on polyacrylamide gels according to Laemmli [21]. Lane 1, 60 $\mu \mathrm{g} 40 \mathrm{~S}_{\mathrm{nd}}$ wash: lane $2,1 \mu \mathrm{g}$ eIF-4C; lane 3,60 $\mu \mathrm{g} 40 \mathrm{~S}_{\mathrm{n}}$ wash. 
$40-S_{n}$ dimers, once isolated, remain dimers upon recentrifugation, whereas apparently homogenous $40 \mathrm{~S}$ monomers are converted into dimers for at least $50 \%$ when subjected to a second centrifugation step (see Fig. 1).

We prepared a $0.5 \mathrm{M} \mathrm{KCl}$ wash from $40-\mathrm{S}_{\mathrm{n}}$ dimers and monomers and checked on polyacrylamide gels for the presence of eIF-4C. The results, indeed, are in line with the hypothesis that removal of eIF.4C results in dimerisation of 40-S subunits (Fig. 6). No eIF-4C could be detected on 40-S dimers (lane 1 ) but almost stoichiometric amounts are present on 40-S monomers (lane 3), as can be deduced by comparison with lane 2 , in which a known amount of eIF. $4 \mathrm{C}$ was electroforesed.

The effect of eIF-4C in assay systems utilizing only 40-S ribosomal subunits, therefore may be explained by its effect on dimer formation, although the physiological relevance of 40-S dimers remain obscure. The significance, however, of the observed stimulatory effect by eIF-4C on the dissociation of $80 \mathrm{~S}_{n}$ is obvious: dissociation of $80 \mathrm{~S}_{\mathrm{n}}$ is a prerequisite for the participation of the ribosome in a new round of initiation. The explanation for both effects on the molecular level might be the same: the presence of eIF-4C on the $40 \mathrm{~S}$ subunit reduces its affinity for both $60-\mathrm{S}$ and other $40-\mathrm{S}$ particles, thus ensuring a proper sequence of initiatory events (see also Eqns. 1 and 2).

\section{Acknowledgements}

We wish to thank M. Kasperaitis and Th. Haubrich-Morree for skilled technical assistance.

\section{References}

1 Anderson, W.F., Bosch, L., Cohn, W.E., Lodish, H., Merrick, W.C., Weissbach, H., Wittman, H.G. and Wool, I.G. (1977) FEBS Lett. 76, 1-10

2 Benne, R. and Hershey, J.W.B. (1978) J. Biol. Chem. 253, 3078-3087

3 Trachsel, H., Erni, B., Schreier, M.H. and Staehelin, Th. (1977) J. Mol. Biol. 116, 755-767

4 Safer, B. and Anderson. W.F. (1978) CRC Crit. Rev. Biochem. 5, 261-290

5 Benne, R., Wong, C., Luedi, M. and Hershey, J.W.B. (1977) J. Biol. Chem. 251, 7675-7681

6 Safer, B., Anderson, W.F. and Merrick, W.C. (1975) J. Biol. Chem. 250, 9067-9075

7 Benne, R. and Hershey, J.W.B. (1976) Proc. Natl. Acad. Sci. U.S.A. 73, 3005-3009

8 Benne, R., Brown-Luedi, M.L. and Hershey, J.W.B. (1978) J. Biol. Chem. 253-3070-3077

9 Voorma, H.O., Thomas, A., Goumans, H., Amesz, H. and Van der Mast, C. (1979) Method Enzym., LX, 124-135

10 Benne, R., Brown-Luedi, M.L. and Hershey, J.W.B. (1979) Method Enzymol. LX, 15-34

11 Bose, K.K., Chatterjee, N.K. and Gupta, N.K. (1974) Method Enzymol. 29, 522-529

12 Stanley, Jr., W.M. (1974) Method Enzymol. 29, 530-547

13 Schreier, M.H. and Staehelin, T. (1973) J. Mol. Biol. 73, 329-349

14 Van der Mast, C., Thomas, A., Goumans, H., Amesz, H, and Voorma, H.O. (1977) Eur. J. Biochem. $75,455-464$

15 Schreier, M.H. and Staehelin, Th. (1973) Regulation of Transcription and Translation, 24 Mossbach Colloquium, pp. 335-349

16 Henshaw, E.C., Guiney, D.G. and Hirsch, C.A. (1973) J. Biol. Chem. 248, 4367-4376

17 Thompson, H.A., Sadnik, I., Scheinbuks, J. and Moldave, K. (1977) Biochemistry 16, 2221-2230

18 Thomas, A., Goumans, H., Amesz, H., Benne, R. and Voorma, H.O. (1979) Eur. J. Biochem. 98 , 329-337

19 Leder, P. and Bursztyn, H. (1974) Biochem. Biophys. Res. Commun. 25, 233-238

20 Naaktgeboren, N., Roobol, K. and Voorma, H.O. (1977) Eux. J. Biochem. 72, 49-56

21 Laemmli, U.K. (1970) Nature 227, 680-685 